\title{
Thin-walled parts CNC Milling Process Analysis and Parameter Optimization
}

\author{
Zhu xiurong \\ College of Mechanical Engineering, Jilin Teacher's Institute of Engineering and Technology, \\ Changchun, Jilin, china 130052 \\ Emai: zxr67811@163.com
}

\begin{abstract}
Through the process of milling of thin-walled parts analysis, developing principles expounded process routes such parts, tool radius compensation and processing methods, etc., using the test method, the process parameters were adjusted and optimization, selecting the optimal parameters then with CAXA manufacturing engineer software simulation and CNC machining automatic programming, machining parts to meet the accuracy requirements. At the same time, improve machine utilization. First, application of research results in the school curriculum and graduation of students training design, with good results. Have practical value. To business promotion, can improve the competitiveness of enterprises.
\end{abstract}

Keywords- Thin-walled parts; CNC Machining; Milling ; Process Analysis; Parameter optimization

\section{INTRODUCTION}

With the development of computer technology, digital control technology has been widely used in various fields of industrial control, especially in the mechanical manufacturing a wide range of applications. Modern manufacturing is an important pillar of the national economy and overall national strength, and China as a manufacturing nation, master advanced digital processing technology and programming technology is also very important.[1] In today's society, complex surfaces used in machinery products more widely, while its processing, cutting conditions are constantly changing, but the current NC machining experience mostly with the choice of cutting parameters ancestors, and in maintain constant process parameters, greatly reducing the productivity of CNC machine tools, through the establishment of optimization system, optimize milling parameters can improve productivity and reduce production costs.[2]

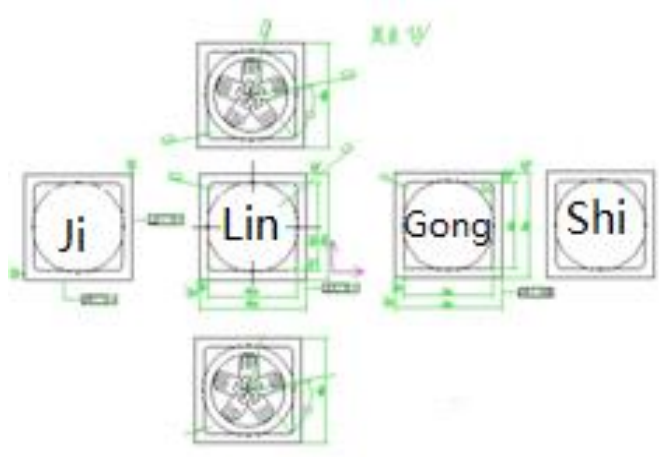

Figure 1. Parts diagram in

\section{THIN-WALLED PARTS CNC MILLING PROCESS ANALYSIS}

\section{A. Analyze parts diagram, determine the installation base}

Parts As shown, there are spherical, square grooves, WordArt and patterns consisting of the part, but also require separate sphere and cube frame. Taking into account the structure and shape of parts, as well as the actual process used in the machining characteristics, select the part of the underside of fixture positioning surface, the fixture clamp using the jaws of death. Taking into account the part length, width and height, respectively, of the maximum size of $70 \mathrm{~mm}, 70 \mathrm{~mm}, 70 \mathrm{~mm}$, so as to select the size of the blank $72 \times$ cylinder. Considering also used in the CNC milling machine processing capacity is not very good and the rigidity is poor, however, parts of the surface roughness, dimensional accuracy and required higher, so the choice of the blank material to aluminum parts, because aluminum good cutting performance parts and do not do heat treatment process.[3]

\section{B. Determine the processing methods and processing line}

\section{1) Select the processing method}

Spherical surface roughness of parts requirements and square grooves, so when milling can be invoked separately roughing, and then finishing the program. Taking into account the selected part of the blank is aluminum, its good machinability and surface without the crust, so the use of the method when Climb milling, this can increase the surface roughness of machined parts and tools can be reduced wear. When text and pattern processing, taking into account the machining accuracy and precision machine tools, you can use the ball-cutter, rough and finish milling process, will be able to meet the requirements of precision parts.

\section{2) Select the processing line}

Determine the route processing, the principles should follow is "first base, after the first hole surface, after the first rough fine." At the time of the square outer contour machining, the use of blanks are aluminum, cutting good, so it should be processed using climb milling processing methods to improve the quality of its processing. Meanwhile, cut and cut out the tool, in order to avoid cutting tool to cut and left into the source and retract the marks, so the tool should be tangential to cut and cut out along parts.

According to the characteristics of the blank, in the process, select the underside as a positioning reference plane, the first of the six parts of the surface contour roughing in chronological order, and then at Calvary 
surface finishing of parts, and then were roughing, finishing within a square contour, the spherical outer contour, finishing in a sphere corresponding text or pattern, and then the workpiece is rotated by 90 degrees corresponding processing until all processing completed up to the respective surface, in the processing of the last portion of a sphere, taking into separate parts, so it is necessary making a special fixture to ensure the positioning accuracy of the workpiece.[4]

\section{Select Cutting}

Because parts of the blank choice is aluminum, so the processing performance of the cutting, the use of processing used machines are $\mathrm{CNC}$ milling machine, taking into account the actual use of vertical milling performance and processing characteristics, its back knife to eat the amount of maximum take is $2 \mathrm{~mm}$, and because the surface roughness of machined parts for the higher, when the need for rough machining, finishing, so when roughing, cutting back the amount of food choice MID is
$1.0 \mathrm{~mm}$, finishing selected finishing allowance of $0.1 \mathrm{~mm}$. Also, because the feed rate of the machine $100 \mathrm{~mm} / \mathrm{min}$, so in order to improve the efficiency of processing, roughing, contour direction selected feed rate (ie FFP1) for $100 \mathrm{~mm} / \mathrm{min}$, feed rate in the depth direction (ie FFD) of $50 \mathrm{~mm} / \mathrm{min}$. In finishing, in order to ensure accuracy and surface contouring, the feed rate of the selected contour direction (ie FFP1) of $80 \mathrm{~mm} / \mathrm{min}$, feed rate in the depth direction (ie FFD) of 40mm / min.

Because the processing of parts and materials for aluminum, its good cutting performance, and the selected feed rate and cutting back the amount of food are relatively small, therefore, the look-up table for reference, the cutting speed can get bigger, so the choice of cutting speed to $160 \mathrm{~m} / \mathrm{min}$. When you select an end mill for milling parts, its spindle speed:

After calculation available, choose their roughing spindle speed 6000r / min, finishing spindle speed 6000r / min. Cutting choose three elements are shown in Table 1

TABLE I. CUTTING THREE ELEMENTS

\begin{tabular}{|l|l|l|l|l|}
\hline & $\begin{array}{l}\text { Spindle speed }(\mathrm{r} / \\
\text { min) }\end{array}$ & Feed rate $(\mathrm{mm} / \mathrm{min})$ & $\begin{array}{l}\text { The back of cut } \\
\text { (each maximum } \\
\text { milling depth) } \\
\text { (mm) }\end{array}$ \\
\hline & & FAL & FALD & \\
\hline Roughing & $\mathbf{6 0 0 0}$ & $\mathbf{1 0 0}$ & $\mathbf{5 0}$ & $\mathbf{1 . 0}$ \\
\hline Finishing & $\mathbf{6 0 0 0}$ & $\mathbf{8 0}$ & $\mathbf{4 0}$ & $\mathbf{0 . 1}$ \\
\hline
\end{tabular}

\section{Select the tool}

Surface milling parts, the use of face milling processing, in order to improve the accuracy of surface machining of parts, to avoid marks at the junction of the tool, so the diameter should be as large as possible to select some of the tool, when the surface milling parts, Select the face milling cutter diameter $50 \mathrm{~mm}$. When milling a square contour, due to restrictions of the spherical contour (sphere radius $30 \mathrm{~mm}$ ), so the contour in the milling, the selected end mill diameter $4 \mathrm{~mm}$. Spherical contour finishing, the choice of $2 \mathrm{~mm}$ diameter ball end mill for processing. In the processing of text and graphics, you can choose a diameter of $1 \mathrm{~mm}$ ball end mill for milling. The carbide cutting tool materials, stiffness, rigidity to meet the requirements of processing. See CNC tool card.[5]

\section{E. Determine the workpiece coordinate system}

Select the center of the upper surface of the workpiece as the origin of the workpiece coordinate system. Shown in the following diagram

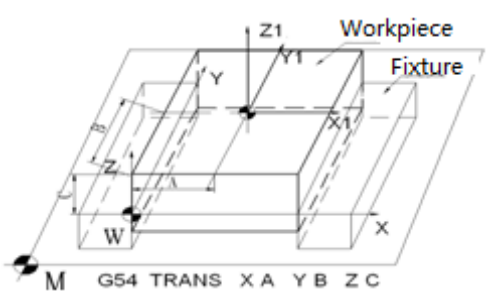

Figure 2. Setting the workpiece coordinate system

\section{F. $\quad$ Milling processes and tool card card}

According to the structure of parts, according to the parts division chucking positioning process, due to the different structure and shape of each part, the technical requirements of each of the machined surface are different, their positioning will have differences. To the bottom and side of the workpiece positioning, were intensified by bench vise. In a process step, press all the machined surface rough finishing first step to divide. 
TABLE II. PARTS CNC MACHINING PROCESS CARD

\begin{tabular}{|c|c|c|c|c|c|c|}
\hline $\begin{array}{l}\text { Workers } \\
\text { No. }\end{array}$ & Step content & $\begin{array}{l}\text { Tool } \\
\text { number }\end{array}$ & Tool Specifications & $\begin{array}{l}\text { Spindle } \\
\text { speed }(r \quad / \\
\text { min) }\end{array}$ & $\begin{array}{l}\text { Feed rate } \\
(\mathrm{mm} / \mathrm{min})\end{array}$ & $\begin{array}{l}\text { The back } \\
\text { of cut } \\
(\mathrm{mm})\end{array}$ \\
\hline 1 & $\begin{array}{l}\text { Roughing the } \\
\text { surface }\end{array}$ & T1 & $\phi 50 F a c e$ milling & 3000 & 100 & 1.0 \\
\hline 2 & $\begin{array}{l}\text { On the surface } \\
\text { finishing }\end{array}$ & $\overline{\mathrm{T} 1}$ & ф 50Face milling & 3000 & 80 & 0.1 \\
\hline 3 & $\begin{array}{l}\text { Square roughing } \\
\text { inner contour }\end{array}$ & T2 & ф 4End Mills & 4000 & 100 & 1.0 \\
\hline 4 & $\begin{array}{l}\text { Finishing square } \\
\text { inner contour }\end{array}$ & T2 & ф 4End Mills & 4000 & 80 & 0.1 \\
\hline 5 & $\begin{array}{l}\text { Spherical contour } \\
\text { roughing }\end{array}$ & T3 & ф 2Ball End Mills & 5000 & 100 & 0.3 \\
\hline 6 & $\begin{array}{l}\text { Finishing } \\
\text { spherical contour }\end{array}$ & T3 & ф 2Ball End Mills & 5000 & 80 & 0.1 \\
\hline 7 & Finishing text & T4 & ф 1Ball End Mills & 7000 & 80 & 0.1 \\
\hline
\end{tabular}

Parts CNC machining tool card is as follows

TABLE III. PARTS CNC MACHINING TOOL CARD

\begin{tabular}{|c|c|c|c|c|}
\hline No. & $\begin{array}{c}\text { Tool } \\
\text { number }\end{array}$ & Tool specifications and name & Quantity & Machined surface \\
\hline $\mathbf{1}$ & $\mathbf{T 0 1}$ & $\mathbf{\phi 5 0}$ Face milling & $\mathbf{1}$ & The rough surface finish on parts \\
\hline $\mathbf{2}$ & $\mathbf{T 0 2}$ & $\mathbf{\phi 4}$ End Mills & $\mathbf{2}$ & Rough finish within a square contour \\
\hline $\mathbf{3}$ & $\mathbf{T 0 3}$ & $\mathbf{\phi 2}$ Ball milling & $\mathbf{2}$ & Rough finishing spherical contour \\
\hline $\mathbf{4}$ & $\mathbf{T 0 4}$ & $\mathbf{\phi 1}$ Ball milling & $\mathbf{2}$ & Text and pattern finishing \\
\hline
\end{tabular}

\section{CAXA MANUFACTURING ENGINEER OPERATION AND PARAMETER SETTINGS}

\section{A. Preparation and processing model}

Former NC programming, must be ready to process models. Processing model preparation, including the establishment of processing models, check with the creation and processing coordinate system. If the boundary contour machining or processing to be carried out locally, you must create an auxiliary line processing.

1) establish a process model

The establishment of processing model may have the following methods.

(1)CAXA manufacturing engineer software modeling based on drawings, directly CAXA manufacturing engineer software modeling.

(2) imported into other CAD software model using the model created with other software can also be used in CAXA manufacturing engineer software. Click [File] $\rightarrow$ [File] command to incorporate pop [Open] dialog box, select the file to be imported.

Although CAXA manufacturing engineer software supports a variety of file formats to import the model, but it is recommended to use other software to store files after format] [*.x_t import CAXA manufacturing engineer software in use.[6]

2) the establishment of processing coordinate system

When using CAM software programming, in order to compile the program is simple, commonly used processing coordinate system (MCS) determine the position of the origin of machined parts. Processing coordinate system determines the tool path zero, the coordinate values toolpaths for machining in homogeneous coordinates. In order to facilitate the knife, the origin of the coordinate system processing is usually set in the center of the upper surface of the blank, Z-axis machining and machine coordinate system must coordinate $\mathrm{Z}$ axis in the same direction.

When using CAXA manufacturing engineer software programming, system coordinate system (sys) can be selected when using modeling or other auxiliary coordinate system as a processing coordinate system.[7]

\section{B. Establish rough}

Must be defined when using CAXA manufacturing engineer software programming blank for trajectory simulation and checked everything.

[Management] in the processing window, double-click on [blank] button, the system definition [blank] dialog box pops up. The system provides three types of blanks defined, respectively [rectangular], [cylinder], [triangle], if you have to draw a model, commonly used reference model bounding box corners under the pickup point or the way.[8] 


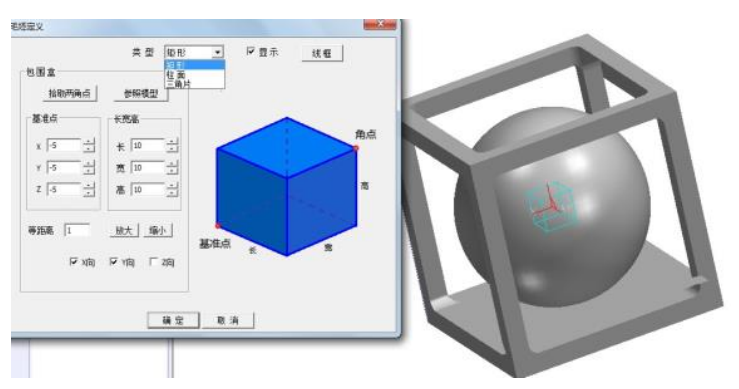

Figure 3. Reference model defines the rough

\section{Establish Tool}

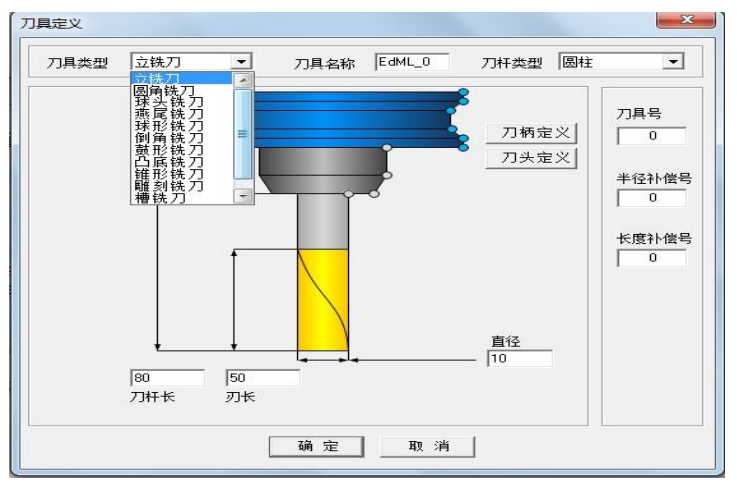

Figure 4. "Tool definition" dialog

In actual production, the processing of a part only possible to use a knife, it is necessary to create the tool according to the machining Parameters tool[9]

The tool library can store different user-defined tools, including drills, cutters, etc., use the user can easily remove the desired tool from the tool library.

Tool type, tool name, the tool number, tool radius $\mathrm{R}$, radius $\mathrm{r} / \mathrm{a}$, cutting length $\mathrm{l}$, the magazine will be the main tool to display the values of these parameters.

Tool parameters: Tool mainly consists of blade holder, the holder of three parts.

Each programming CAXA manufacturing engineers tool parameters are included option, its role is to determine the tool used in machining.

Click Parameters tool button to enter the editing interface tool. [Type] option in the tool, select the desired type of tool. The basic dimensions of the tool for editing.[10]

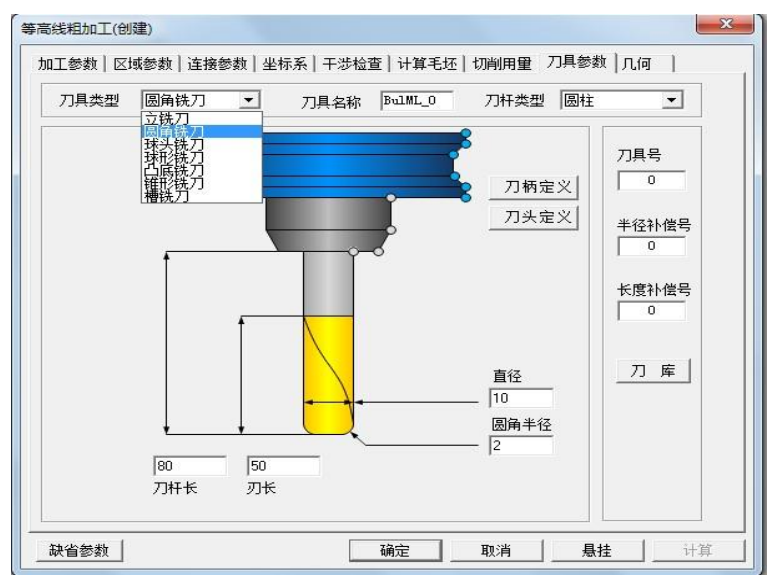

Figure 5.Tool parameters

\section{CONCLUSION}

Analysis of thin-walled parts processing of the key issues process analysis and optimization of process parameters selection. Analysis processing parts, select processing methods to determine the processing parameters, path generation and simulation, after generating toolpaths, the need for machining process simulation trajectory, through a lot of the actual cutting process simulation and processing results can be checked for correct processing path resistance, processing accuracy and productivity. First, application of research results in the school curriculum and graduation of students training design, with good results. Have practical value. To business promotion, can improve the competitiveness of enterprises. The following conclusions:

(1) contour is more complex, before programming, a thorough analysis of the main processing and parameter settings, automatic programming can solve the problem of programming

(2) automatic programming software can be modified parameters, the simulation process is repeated, parameter optimization to ensure the correctness of the program.

(3) in the process parameters can be revised to optimize parameters, saving processing materials, increase productivity, improve the utilization of the machine, has a very important practical significance.

(4) for programming complex parts, especially thin-walled parts, its technical and economic benefits are significant.

(5) text parameter values can be optimized as CNC

Machining reference value.

In short, spare parts processing technology to develop a reasonable or not, select the appropriate parameters or not, for the part programming, machining accuracy and efficiency of the machining of parts have a significant impact.

\section{REFERENCES}

[1] Yu Jie, Xu Guanghui CNC Machining technology and programming, Beijing: National Defense Industry Press, 2010.1

[2] Pu Yan Min, Jiang Fang CNC milling practical skills, Beijing: Mechanical Industry Press, 2010.10

[3] Wu Lei. China today to explore CAM software [J]. Electronics and Software Engineering, 2014,01: 99.

[4] Han Hung Luen Wang Changyi, Wu Haiyan CNC milling / machining center operator full technician training course, Beijing: Chemical Industry Press, 2009.6.

[5] Tang Jinyuan, Huang Yunfei, Zhou Chao, et al. Spiral bevel gear tooth surface geometry modeling [J]. Computer simulation , 2009, 26 (2):293-297

[6] Ji Yanqiao CAD / CAM application technology -CAXA CAXA manufacturing engineers and NC 2008, Beijing: Chemical Industry Press, 2009.11.

[7]He Dazhi, Pan Yuxue, Zhang Liang, et al. Spiral Bevel Gear Solid Modeling Based on Y2280 machine [J]. Journal of Changchun University of Science and Technology (NATURAL SCIENCE EDITION), 2008, 31 (3):122.124

[8]Zhu Mo Parametric Design and automatic programming system developed non-circular gear[D] Instructor: Liu Yongping, Lanzhou University of Technology, 2013.

[9] Wang Huaqiao, Zhang Ying, Wang Deyue. Typical CAM CNC Milling programming platform feature comparison CAD / CAM and manufacturing information .2006, No.4: $78 \sim 82$ 
[10] Zhu Xiurong Experimental study of complex parts CNC milling and processing of automatic programming $[\mathrm{J}]$ Jilin Engineering and
Technical Teachers College, 2011,12: 71-73 